\title{
EPISTEMOLOGIA DOS OLHARES AMAZÔNICOS
}

\author{
EPISTEMOLOGY OF THE AMAZON IMAGERIES
}

\author{
EPISTEMOLOGÍA DE LAS MIRADAS AMAZÓNICAS
}

\author{
João Carlos Gomes \\ Pós_Doutorado em Educação e Interculturalidade - UCDB/MS. Doutorado em Ciências - UFSCAR. \\ Professor da Universidade Federal de Rondônia - UNIR. \\ E-mail: joaoguato@gmail.com \\ Neide Borges Pedrosa \\ Doutora em Educação - PUC/SP \\ Professor assistente da Universidade Federal de Rondônia - UNIR \\ neibpedrosa@gmail.com \\ Noraides Ferreira de Almeida \\ Mestrando em Letras \\ Universidade Federal de Rondônia - UNIR \\ Mestrado Acadêmico em Letras (ML) \\ norinha6@hotmail.com
}

\begin{abstract}
RESUMO
O presente estudo representa um esforço destes pesquisadores na construção de olhares sobre as epistemologias amazônicas como ensaio de interpretação dos saberes amazônicos. É uma tentativa de construção de saberes visando produzir novas metodologias de ensino e aprendizagem voltados à educação escolar. A pesquisa parte do pressuposto de que, para se pensar na educação escolar no ambiente amazônico, é preciso reconhecer a diversidade cultural dos povos amazônicos. Para avançar nesta perspectiva é necessário dar visibilidade às vozes amazônicas, revelando as diversas formas de manifestações culturais interpretadas pelo arcabouço teórico da sociopoética, com categorias de análise dos estudos de inspiração etnográfica. O nosso objetivo com o estudo da epistemologia dos olhares amazônicos, pretende promover a linguagem visual de maneira crítica e dialógica, com base nos saberes do bioma amazônico. Entendemos que as epistemologias amazônicas contribuem para a promoção de diálogos interculturais, que habilitam os sujeitos a crescerem com autonomia pedagógica na construção de narrativas imagéticas culturais, que podem contribuir com os processos de ensino e aprendizagem de forma criativa e prazerosa. Nesse sentido, o presente artigo busca refletir, na perspectiva dos estudos culturais pós-críticos, as diversas expressões dialógicas da subjetividade imagética, para a consolidação da leitura do mundo e da palavra para além dos ambientes escolares.
\end{abstract}

Palavras-chave: Educação escolar; Pedagogia visual; Epistemologias amazônicas.

\begin{abstract}
The present study represents an effort of these researchers in the construction of glances on the Amazonian epistemologies as an attempt to interpret Amazonian knowledge. It seeks out to build a new knowledge in order to produce new teaching and learning methodologies for school education. The research is based on the assumption that in order to think about school education in the Amazonian environment, it is necessary to recognize the cultural diversity of the Amazonian peoples. To advance in this perspective, it is necessary to give visibility to the Amazonian voices, revealing the diverse forms of cultural manifestations interpreted by a
\end{abstract}


theoretical framework of sociopoetics with the categories of analysis of studies of ethnographic inspiration. Our objective with the epistemology of Amazonian I imageries is to promote the visual language in a critical and dialogical way based on the knowledge of the Amazonian biome. We understand that the Amazonian epistemologies contribute to the promotion of intercultural dialogues that enable subjects to grow with pedagogical autonomy in the construction of imagistic cultural narratives that can contribute to the teaching and learning processes in a creative and pleasurable way. In this sense, the present article aims to reflect in the perspective of the post-critical cultural studies, the various dialogical expressions of the imaginary subjectivity for the consolidation of the reading of the world and the word beyond the school environments.

Keywords: School education; Visual pedagogy; Amazonian epistemologies.

\section{RESUMEN}

El presente estudio representa un esfuerzo de estos investigadores en la construcción de miradas sobre las epistemologías amazónicas como ensayo de interpretación de los saberes amazónicos. Es un intento de construcción de saberes para producir nuevas metodologías de enseñanza y aprendizaje dirigidos a la educación escolar. La investigación parte del supuesto que, para pensar sobre la educación escolar en el ambiente amazónico, es preciso reconocer la diversidad cultural de los pueblos amazónicos. Para avanzar en esta perspectiva es necesario dar visibilidad a las voces amazónicas, revelando las diversas formas de manifestaciones culturales, interpretadas por el marco teórico de la sociopoética, con categorías de análisis de los estudios de inspiración etnográfica. Nuestro objetivo con el estudio de la epistemología de las miradas amazónicas, pretende promover el lenguaje visual de manera crítica y dialógica, con base en los saberes del bioma amazónico. Entendemos que las epistemologías amazónicas contribuyen para la promoción de diálogos interculturales que habilitan a los sujetos a crecer con autonomía pedagógica, en la construcción de narrativas imagéticas culturales, las cuales pueden contribuir con los procesos de enseñanza y aprendizaje de forma creativa y placentera. En este sentido, el presente artículo busca reflejar, en la perspectiva de los estudios culturales post-críticos, las diversas expresiones dialógicas de la subjetividad imagética, para la consolidación de la lectura del mundo y de la palabra más allá de los ambientes escolares.

Palabras-clave: Educación escolar; Pedagogía visual; Epistemologías amazónicas.

\section{CONSTRUINDO CAMINHOS PARA ECOLOGIA VISUAL}

O século XXI consolidou-se como a era digital devido à presença em massa das novas tecnologias de informação, comunicação e expressão na educação (NTICE). Esse é um processo irreversível, que deve ser enfrentado no campo da teoria do conhecimento tecnológico, como movimento de ampliação também das ciências humanas na área da educação. Mesmo considerando que as tecnologias entraram em nosso continente sem que as sociedades nacionais pudessem exercer a sua função soberana de selecioná-las e decidir sobre seus usos e aplicações, as novas tecnologias na educação são uma realidade que não 
pode mais ser negada. Até nas periferias dos centros urbanos as novas tecnologias são uma realidade da virtualização da sociedade atual.

Sabe-se da inserção das novas tecnologias nos países industrializados na década de 70, em decorrência dos avanços tecnológicos da indústria eletrônica. Depois disso, nas décadas que se seguiram, as novas tecnologias tiveram o seu consumo massificado, penetrando na sociedade brasileira de forma colossal a partir da década de 90. Mesmo assim, os avanços das pesquisas e das ciências pouco têm contribuído para a diminuição da desigualdade na sociedade atual. Isso devido às ações das políticas desenvolvimentistas neoliberais, que não vêm levando em consideração o conhecimento científico na construção das políticas públicas. Essa constatação nos mostra que é preciso inovar nossas estruturas para exercer um papel de manutenção do planeta em sua plenitude (cf. GOMES; SATO, 2001, p. 13).

Dessa forma, os estudos nos campos da diversidade da educação escolar com suas relações interculturais podem contribuir para o resgate de valores e atitudes intrínsecos às epistemologias dos olhares amazônicos. Reconhecemos que a diversidade do conhecimento cultural é de fundamental importância para a identificação dos saberes amazônicos visando à construção de horizontes plurais nos ambientes amazônicos mediados pelas narrativas imagéticas.

Neste estudo reivindicamos os paradigmas da educação ambiental como pressuposto para reflexão sobre as epistemologias dos olhares amazônicos. Na perspectiva da pesquisa em educação ambiental (EA), Sato (1998, p. 8) nos ensina que "embora os trabalhos tradicionais em EA sejam direcionados muito mais para um campo das ciências naturais, não resta dúvida de que há uma tendência internacional para reparar esse determinismo ecológico". Dessa forma, a autora comenta que, para aqueles que se aventuram a trabalhar nesse espaço híbrido, o desafio sempre ocorre no reconhecimento das forças que atuam contra ou a favor do sistema neoliberal. Todavia, podemos dizer que nos campos híbridos da EA não existe neutralidade: ou você está a favor ou contra o sistema. Por isso reivindicamos os paradigmas da pesquisa em educação ambiental na promoção de diálogos interculturais, no âmbito das ciências sociais em educação com sua diversidade 
de cultura, raça e etnias.

Sauvé (2005, p.17) nos alerta que, quando se aborda o campo da EA, podemos nos dar conta de que, apesar da sua preocupação comum com o meio ambiente e do reconhecimento do papel central da educação para a melhoria da relação educativa, os diferentes autores adotam diferentes discursos sobre a EA e propõem diversas maneiras de se conceber e de se praticar a ação educativa. Com isso, acreditamos que as relações do multiculturalismo reivindicado pela educação intercultural encontram-se contempladas pelo olhar epistemológico dos paradigmas da educação ambiental na perspectiva crítica de pensar a educação.

Assim, esses pesquisadores acreditam que é possível que cada um apresente a sua própria visão pedagógica e a maneira que considere correta para realizar a práxis educativa no âmbito da educação escolar, com a identificação dos saberes amazônicos. Por isso, podemos afirmar que EA trilha campos híbridos da epistemologia que nos permitem reinventar caminhos educativos entre a prática e a teoria. Temos assim o que Sauvé (op. cit.) classifica como diversos territórios pedagógicos, o que nos deixa livres para escolher estratégias e possibilidades teóricas e práticas no campo da educação ambiental. São muitas as possibilidades que temos para educar dentro de uma variedade de métodos que nos revelam a paixão pelo possível.

Para este estudo, que pretende propor a construção de uma pedagogia imagética, fizemos a opção pela corrente da ecoeducação, que reivindica os paradigmas da educação, porque não se trata de resolver problemas e sim de aproveitar a relação didática que a temática do meio ambiente possibilita como esfera de interação social, econômica, política e cultural. Gadotti (2009, p. 6), numa reflexão pedagógica sobre o cuidado que devemos ter com o planeta Terra, convoca a humanidade para a construção de uma “ecopedagogia” e

1 A ECOPEDAGOGIA é um conceito em construção e é definido mais como um movimento do que como uma nova teoria de educação. No Brasil, o principal centro de estudos sobre a Ecopedagogia é o Instituto Paulo Freire, em cujo site existe uma série de documentos e artigos sobre o tema, entre eles "Pedagogia da Terra - ideias centrais para um debate”, de Moacir Gadotti, professor titular da Universidade de São Paulo e Diretor do Instituto Paulo Freire. Segundo Gadotti, a ecopedagogia não é uma pedagogia a mais, ao lado de outras pedagogias. Ela só tem sentido como projeto alternativo global em que a preocupação não está apenas na preservação da natureza (Ecologia Natural) ou no impacto das sociedades humanas sobre os ambientes naturais (Ecologia Social), mas num novo modelo de civilização sustentável do ponto de vista ecológico (Ecologia Integral) que implica uma mudança nas estruturas econômicas, sociais e culturais. Ela está ligada a um projeto utópico: mudar as relações humanas, sociais e ambientais que temos hoje, esse é o sentido profundo da Ecopedagogia, ou de uma Pedagogia da Terra, como a chamamos. 
uma ecoformação ${ }^{2}$ dos seres humanos, que possibilitem a construção de alternativas pedagógicas para a reeducação de homens e mulheres, principalmente o homem ocidental, prisioneiro de uma cultura predatória.

Assim, ele comenta que "sem uma educação sustentável, a Terra continuará apenas sendo considerada como espaço de nosso sustento e do domínio técnico-tecnológico, objeto de nossas pesquisas, ensaios e, algumas vezes, de nossas contemplações. Mas não será o espaço de vida, o espaço do aconchego, de cuidado". Com isso, nos indica que o caminho para a construção do quinto elemento é o amor para com a terra, pois quem não ama não cuida.

Um bom exemplo dessa abordagem encontra-se na produção acadêmica em ecologia humana de Maroti (1997, p. 13) que, ao estudar as relações das populações humanas com áreas de preservação permanente, diz que os estudos das relações humanas dessas populações com os ambientes naturais e culturais contribuem para uma utilização mais racional dos recursos ambientais, o que possibilita uma relação de equilíbrio dos conhecimentos locais do interior com os conhecimentos do exterior enquanto instrumento educativo e agente de transformação social. Dessa forma, o autor nos remete à ecoformação ao comentar que as condições para o aumento de conhecimento das relações ambientais facilitam a integração das populações biorregionais ${ }^{3}$ com o entorno das Unidades de Conservação (UC).

Diante dessa diversidade de perspectivas pedagógicas sobre os ambientes naturais e culturais, ousamos ampliar o nosso olhar pedagógico de educador ambiental em busca de resposta teórica para instrumentalizar a defesa da imagem fotográfica como instrumento didático-pedagógico de "sensibilização ambiental”, dentro dos paradigmas da educa-

2 ECOFORMAÇÃO - É um conceito trabalhando por Gaston Pineau (1992) nos ensina que a ecoformação pode ser definida como a formação recebida e construída na origem das relações diretas com o ambiente material: os não humanos, os elementos, a matéria, as coisas, a paisagem. Dessa forma, o conceito é entendido como o processo de Formação Humana Permanente. Assim, a ecoformação não é apenas um processo educativo de formação para o trabalho, mas um processo mediador da relação de homens e mulheres com seus ambientes sociais e naturais.

3 BIORREGIONALISMO - GARY SNYDER (1993) traz a principal defesa do biorregionalismo, partindo do princípio revolucionário de que o lugar é parte do que somos, essa "instituição comunitária tradicional", livre da força e presença de um Estado, respeita e inclui os não humanos, presentes em sua biorregião, numa consciência de preservação enraizada no suprir e prover, e, não, no explorar. Por isso, Snyder propõe um contrato mundial em defesa dos recursos e dos povos naturais, de forma a garantir que apenas as comunidades enraizadas nas biorregiões tenham direito ao uso dos bens regionais. 
ção ambiental sustentada numa ecopedagogia. É uma tentativa destes pesquisadores que ousam a transmutação do olhar educativo no sentido da consolidação de uma pedagogia que no futuro possa ser classificada como movimento de reinvenção educativa, rumo à consolidação da "pedagogia visual".

O nosso propósito com este estudo é ousar na quebra dos paradigmas do pensamento epistemológico cartesiano e mergulhar na busca de uma reinvenção pedagógica com o uso da imagem fotográfica na construção do pensamento educativo da pedagogia visual. Freire (1979) nos ajuda nesse sentido, ao nos mostrar que é possível a reinvenção do ato educativo. Mas para isso se exige do pesquisador uma postura alicerçada num processo permanente de ação e reflexão, que leve a resultados inovadores no trato da educação.

Dessa forma, não resta dúvida de que as contribuições do pensamento de Paulo Freire nos ajudam nas reflexões acerca da consciência de si enquanto ser histórico, que continuamente se educa num movimento da educação permanente. Não é, pois, por acaso que as ideias freireanas se articulam com os interesses na formação do educador ambiental, pois não se perde de vista o caráter histórico do ser humano associado sempre à prática social do lugar em que vive.

No pensamento pedagógico de Paulo Freire (op. cit.) aprendemos que o diálogo não é só uma qualidade do modo humano de existir e agir. O diálogo é a condição disso, o que torna humanos os homens e as mulheres como partes diversas da Terra. E o relacionamento do pesquisador como sujeito e sujeito da pesquisa precisa estar pautado no diálogo, para que os indivíduos se posicionem no ato do conhecimento, numa relação horizontal. Com isso, a ideia do tradicional (cartesiano) que permeava a relação educativa precisa ser banida para dar lugar à pedagogia do diálogo, num movimento permanente em estado de metamorfose. E essa relação não acontece de forma imposta, ela ocorre naturalmente quando educando e educador conseguem se colocar na posição do outro, tendo a consciência de que ao mesmo tempo são educandos e educadores.

O presente artigo apresenta algumas reflexões sobre o uso das imagens como instrumento didático-pedagógico e como suporte de informação, comunicação e produção de mídias para os processos de ensino e aprendizagem no âmbito escolar. O nosso propósi- 
to é contribuir com uma reflexão teórica sobre as potencialidades do uso da imagem como meio de divulgação e inserção no mundo contemporâneo.

\section{Materiais e métodos}

O presente estudo, sob a perspectiva dos estudos culturais pós-críticos, tem como opção a “epistemo-metodológica” sustentada por um arcabouço teórico de inspiração etnográfica com base na sociopoética (GAUTHIER et al, 2001), o que dispensa longas teorias para justificar que o objetivo maior é realizar interpretação dos olhares amazônicos, de modo que as pessoas possam aprender participando como sujeitos da pesquisa e se apropriar dos resultados finais. Diferentemente de um grupo de pesquisa ou de intervenção educativa para identificar um problema, o nosso propósito é fazer reflexões que possam oferecer outros olhares etnográficos sobre o ambiente amazônico, para a criação de uma comunidade interpretativa de aprendizagem (RUIZ, 2005) das observações etnográficas voltadas para os diversos ambientes amazônicos.

Como o presente estudo é orientado pelos paradigmas dos Estudos Culturais pós-críticos, reafirma-se que seu objetivo maior é que as próprias pessoas envolvidas vão aprendendo, participando e se apropriando, de forma coletiva, dos resultados construídos. Reconhecemos que essa metodologia de pesquisa é um tanto desafiadora, pois abre caminhos para a utilização de pressupostos e premissas teóricas, que permitem a criação de procedimentos metodológicos para a produção dos dados e das análises utilizando estratégias de acordo com as necessidades da pesquisa (PARAísO, 2012).

Meyer e Paraíso (2012) asseguram que as pesquisas que utilizam os estudos pós-críticos deixam o percurso da pesquisa em aberto, não estabelecendo um caminho completamente trilhado, estabelecido, concretizado, rígido, para que o pesquisador se sinta livre para reorganizar, repensar, reavaliar e replanejar a pesquisa sempre que houver necessidade, sem que isso seja considerado uma ruptura da metodologia estabelecida previamente. Nesse prisma, as pesquisas pós-críticas permitem a criatividade epistemológica para a construção dos caminhos, sem perder a rigorosidade acadêmica na construção do 
pensamento científico.

\section{Um olhar amazônico para a epistemologia da cultura visual}

Na reivindicação da construção da pedagogia visual como uma proposta educativa para a cidadania planetária, demanda-se que haja muito mais uma construção filosófica educacional do que o enunciado de princípios educativos. Ou seja, a construção de movimentos que implicam uma revisão dos nossos currículos, uma reorientação de nossa visão de mundo sobre a educação como espaço de inserção do indivíduo, não numa comunidade local e sim numa comunidade que é local e global, sem perder o foco dos valores biorregionais. Com isso, não reivindicamos um movimento pedagógico para a simples transmissão da cultura de uma geração para outra, mas uma aventura pelos campos de incerteza de cada indivíduo no seu universo interior e no universo que o cerca. Acima de tudo, uma educação que seja prazerosa e dialógica na práxis educativa.

Os paradigmas de uma ecopedagogia nos permitem entrar num movimento que amplia novos desdobramentos. Nas trilhas da ecopedagogia, não podemos afirmar que a pedagogia visual não é mais uma pedagogia entre tantas pedagogias que podemos e devemos construir. Ela só tem sentido como uma ação do paradigma da sensibilização pela educação ambiental, que seja capaz de tornar-se campo da educação permanente num projeto pedagógico alternativo, em que a preocupação não esteja apenas na preservação da natureza (Ecologia Natural) ou no impacto das sociedades humanas sobre os ambientes naturais (Ecologia Social), mas na contribuição de um novo modelo de sociedade sustentável do ponto de vista ecológico (Ecologia Integral), o que implica uma mudança nas estruturas econômicas, sociais e culturais. Ela está ligada, portando, à utopia da ecopedagogia de tentar mudar as relações humanas, sociais e ambientais que temos hoje, no contexto da educação permanente.

Nossa busca teórica é no sentido de mostrar um novo modelo de sociedade sustentável do ponto de vista da pedagogia visual, voltado para a mudança das práticas educativas dentro dos currículos educativos que refletem as estruturas econômicas, sociais e 
culturais. Nessa caminhada da pedagogia visual, o nosso desejo utópico de pesquisadores apaixonados pela educação ambiental visa tentar, por meio das imagens fotográficas, construir elementos didáticos que contribuam com a sensibilização das pessoas nas relações humanas, sociais e ambientais, utilizando tais imagens como instrumento de sensibilização ambiental.

Com o olhar da pedagogia visual como instrumento didático para a sensibilização ambiental, Delgado (2002, p. 23) nos revela que o conhecimento imagético nos ensina que “existe algo de surpreendente na fotografia, algo de revelador, de inédito, já que o momento da sensibilização do fotograma não é visto pelo olho do fotógrafo, ele só enxerga o antes e o depois. No momento que antecede a sensibilização, o olho enquadra, recorta, define a exposição e a velocidade de captação, assim se dá o registro, ou melhor, a troca entre as diferentes linguagens", que nos permite abrir a janela da alma das pessoas para a revelação dos graves problemas ambientais que afetam a humanidade.

Nessa perspectiva, a sensibilização humana pelo registro do olhar fotográfico, ao mesmo tempo que reflete certo recorte particularizado do passado, abre também um amplo leque de possibilidades para que se rememorem outros aspectos que não foram plenamente mensurados na época em que a fotografia foi tirada. Dessa forma, podemos criar um movimento ancorado na ecopedagogia que é mais amplo e pode superar o antropocentrismo das pedagogias tradicionais e conceber o discurso imagético que envolve o ser humano em sua diversidade e em relação com a complexidade da natureza. Então, a sensibilização imagética passa a ser considerada o instrumento educativo capaz de sensibilizar os seres humanos para a tomada de decisões em defesa dos ambientes naturais e biorregionais dos ecossistemas do planeta Terra.

\footnotetext{
A fotografia, apesar de possuir uma imagem materialmente lotada (depois da revelada não se pode acrescentar mais nada à sua face), não se esgota no papel que a sustenta. Primeiro porque só tiramos uma foto a partir de algum tipo de demanda e interesse. Ou seja, eleger um momento para fotografar significa de alguma forma revelar saberem possíveis (ibidem, 2002. p. 3).
}

Na tentativa de compreender a imagem fotográfica como instrumento didático de sensibilização ambiental, para a tomada de decisão no marco da consciência política dos 
graves problemas ambientais que afetam a sociedade planetária, Barreto \& Barreto (2002, p. 43) asseguram que "a imagem fotográfica busca unir a antropologia e a fotografia registrando instantes culturalmente eloquentes com domínio dos efeitos de sentido (geralmente intuitivo) produzindo fotos que consigam mobilizar intelectual e emocionalmente o receptor, atingindo-o como uma picada".

Dessa forma, o discurso imagético nos campos híbridos da educação ambiental pode incorporar a ecopedagogia como paradigma do movimento da pedagogia visual para oferecer estratégias, propostas e meios para sensibilização dos seres humanos quanto ao cuidado ambiental com o planeta Terra. Com esses meios, podemos educar para a cidadania planetária. Isso pressupõe o entendimento de que precisamos melhorar a qualidade de vida no planeta. Mas também precisamos viver permanentes e complexas relações entre nós mesmos e as outras formas de vida, numa simbiose em que nós, seres humanos, incorporamos a outro ser, que também está vivo, que nos acolhe e nos mantém vivos e se mantém vivo (GADOTTI, 2009).

Assim, essa abordagem imagética rumo à construção de uma pedagogia visual possibilita a criação de um novo instrumento pedagógico, que visa despertar graus mais elevados para a construção de novas práxis de sensibilização para as práticas de educação ambiental. Isto porque a EA cria condições para fomentar novas atitudes nos sujeitos sociais e novas decisões da sociedade, guiadas pelos princípios da sustentabilidade ecológica e da valorização da diversidade cultural dos diversos ecossistemas (SANTOS; SATO, 2001).

Assumimos que a fotografia na dinâmica da EA possui uma temporalidade, uma territorialidade, uma identidade e um olhar perceptivo da fenomenologia. A nossa intenção é tentar unir a etnografia à imagem, ambas mergulhadas em sentidos polissêmicos dos instantes culturalmente eloquentes, tanto para o transmissor da linguagem como para o receptor da mesma iconografia (BARRETO; BARRETO, 2002). É, sobremaneira, a dramática vontade de revigorar sentidos, muitas vezes adormecidos na insensibilidade cotidiana, que emerge na síntese da luz para a compreensão das antíteses de múltiplos olhares existentes numa mesma paisagem, jamais estática ou completa.

Não resta dúvida que a fotografia é uma expressão didática que pode traduzir os 
esforços humanos para decifrar um destino, guiando na superação dos labirintos, mas que também viabiliza o sonho (BACHELARD, 1988). As percepções humanas sempre se sentem enganadas pelos sentidos. Há sempre um espaço de dúvida na mente humana sobre as percepções dos sentidos e, portanto, esconder a tendência ideológica desta metodologia será uma irresponsabilidade ética imperdoável. A fenomenologia, entretanto, é compreensiva e não explicativa, o que, de certa forma, exime as culpas do excesso científico exigido pelas mentes cartesianas. Talvez a política correta não seja remendar subjetividade com objetividade, mas "a política correta é regressar a uma etapa muito anterior e demolir a doutrina científica ortodoxa em sua totalidade antes que ela alce voo".

\section{A diversidade de olhares de mulheres e homens no bioma amazônico}

Com objetivo de compreender melhor os homens e as mulheres do bioma amazônico como partes integrantes da diversidade da Terra, buscamos identificar subsídios para a construção de propostas pedagógicas rumo à consolidação de uma pedagogia da ecologia visual com base na diversidade de olhares amazônicos. A ideia central é contribuir com a construção de sociedades sustentáveis baseadas no etnoconhecimento biorregional, que levem em conta o "etnos" na "oikos" sem imposições externas, cujos objetivos interdisciplinares buscam uma ponte entre as ciências sociais e as ciências biológicas, numa interface com os paradigmas da educação ambiental, com recortes das concepções da diversidade de olhares das epistemologias amazônicas.

Reconhecemos que a condição atual do meio ambiente não é um produto da natureza, mas das diversas formas de organização social que, no processo de utilização desta, utilizam-se não somente de tecnologias como também de sistemas simbólicos e de representações mentais do mundo natural. Ao agirem sobre a natureza, as sociedades dispõem de representações mentais sobre significados e finalidades do mundo natural, sistemas simbólicos esses que variam de sociedade para sociedade, segundo os tempos históricos. Nesse sentido, mudar as relações humanas passa necessariamente por alterações nesse complexo simbólico (DIEGUES, 2002). 
Nesse universo simbólico de busca de novas alternativas pós-críticas, a opção aqui é cruzar as interpretações das leituras etnoecológicas na abordagem da antropologia interpretativa (MERLEAU-PONTY, 1971), para a determinação de um método que pressuponha equilíbrio, estabilidade e funcionalidade nas luzes do conhecimento científico, das interpretações das narrativas imagéticas dos ambientes naturais e culturais, visando à sensibilização ambiental.

Nesse contexto epistemológico dos olhares amazônicos, é essencial compreendermos a diversidade de olhares amazônicos na perspectiva da etnoecologia. Para Marques (1995), “o conhecimento ecológico tradicional (biorregional) refere-se ao conhecimento adquirido por povos indígenas e locais, por meio de séculos de experiências diretas e de contato com o meio ambiente". Para o autor, o etnoconhecimento assume diversas formas, a saber: um íntimo e detalhado conhecimento do ambiente natural; o desenvolvimento e o uso de tecnologias apropriadas para a caça, a pesca, a agricultura e o reflorestamento; e um conhecimento holístico ou "uma visão de mundo" que se paralisa ante a disciplina científica da ecologia.

Etnoecologia é o estudo das interações entre a humanidade e o resto da ecosfera, através da busca da compreensão dos sentimentos, comportamentos, conhecimentos e crenças a respeito da natureza, características de uma espécie biológica. [...] Sua ênfase, pois, deve ser na diversidade biocultural e o seu objetivo principal a integração entre o conhecimento ecológico tradicional e o conhecimento ecológico científico (MARQUES, 1995, p. 35).

Numa perspectiva mais prática, procurou-se sintonizar que a etnoecologia é o estudo científico do conhecimento biorregional das comunidades pantaneiras. Com essa base, é que se partiu para a concretização do objetivo de contribuir para uma compreensão dos fenômenos despertados no modo de vida pantaneiro, especificamente no que diz respeito à singularidade do viver dos vários pantanais no ecossistema de área úmida da planície pantaneira. Em outro contexto, pretende-se compreender a dinâmica cultural e os aspectos cognitivos desse importante ecossistema que se transformou em reserva da biosfera.

Na perspectiva dos olhares estruturalistas, o bioma amazônico é santuário ambiental carregado de saberes religiosos que definem a preservação dos recursos naturais na 
perspectiva do pensamento cristão, dos mitos e das lendas amazônicas. O olhar fenomenológico nos convida a compreender que há sempre um protetor ou uma entidade que justifica os fenômenos naturais. É nesse espaço de sincretismo religioso que encontramos diversos saberes que defendem a necessidade de preservação do bioma amazônico como santuário ecológico da humanidade no planeta Terra. Esses saberes reconhecem na Amazônia um santuário intocável, a exemplo do seu status de "patrimônio da humanidade", a santidade semiológica que se entrecruza com a exuberância ecológica, revelando o sentido etimológico do santuário: é como se as raízes das árvores e da vegetação mergulhassem na terra com sua copa tocando o céu. E, no meio desse espaço, concretiza-se o território intermediário da luta humana protegido pelas suas divindades.

Seria um equívoco acreditar que a religiosidade "mascara a luta política” explícita na vida das comunidades amazônicas. Inseridas em projetos de Educação Ambiental (EA), as pessoas se recusam a aceitar o inexorável movimento da globalização, projetado na homogeneidade da solidariedade absoluta entre todos os povos, da eliminação das diferenças e da pulsação que segrega o local do global. Com isso, podemos reconhecer que, entre o desejo do ideal e o concreto, há um abismo que precisa ser superado. A mudança de uma sobrevivência predatória a uma vida ética requer instrumentos de educação ainda em plena construção local. Isso não implica, entretanto, desprezar a cidadania planetária, mas, antes, institui-se o desafio de sermos realmente justos em construir a requerida cidadania local.

Compreendemos que na riqueza das experiências realizadas no projeto comunitário de EA há também o paradoxo da estagnação. Se alguns olhares percebem o conhecimento indígena ou popular como "tradicional”, ou "primitivo", é preciso problematizar que essa assimetria esconde uma hierarquia perversa da superioridade de quem estabelece e determina a contemporaneidade. A contração do mundo, sob a égide dos controles dominadores, "esconde a riqueza das experiências sociais do mundo... pois as entidades ou experiências específicas estão aprisionadas em escalas que as incapacitam de serem alternativas críveis na racionalidade universal e dominante" (SANTOS, 2000, p. 49).

No olhar das epistemologias pós-críticas sobre o ambiente amazônico, reivindica- 
mos a necessidade de narrativas imagéticas construídas na metamorfose dos olhares dos povos amazônicos. Esses olhares revelam os signos presentes em várias formas de linguagem e dão forma aos desejos, às esperanças - modelam atitudes e soltam nossa liberdade de voo. "Todo exercício fotográfico é um registro para a posteridade, uma tentativa de negar a morte" (REZNIK; GONÇALVES, 2005, p. 3).

Dessa forma, as narrativas imagéticas podem metaforicamente ser representadas pela fotossíntese, elas são uma expressão iconográfica que pode traduzir os esforços humanos para decifrar um destino, guiando na superação dos labirintos, mas que também viabilizam o sonho (BACHELARD, 1988).

\section{A iconografia do olhar sobre as linguagens do corpo 4 das mulheres Karitiana}

Nessa perspectiva das epistemologias dos olhares amazônicos, reconhecemos que a linguagem do corpo é um processo histórico de constituição da ciência que vem adquirindo destaque nos estudos culturais relacionados às áreas de educação e linguagem. Entre as várias áreas de estudo da educação escolar indígena, por exemplo, a área de linguagem, no contexto dos processos próprios de ensino e aprendizagem, é um campo fértil de pesquisa e estudos que pode contribuir com a melhoria da qualidade da educação escolar indígena no bioma amazônico.

Visando compreender a diversidade de saberes amazônicos relacionados aos estudos culturais na construção das identidades das mulheres Karitiana, passamos agora a refletir sobre a linguagem do corpo na produção dos processos próprios de ensino e aprendizagem no contexto da educação indígena. Temos a compreensão prévia de que este estudo passa necessariamente pelos pressupostos dos estudos da identidade feminina em relação ao corpo na configuração das linguagens utilizadas para os processos próprios de ensino e aprendizagem.

Do ponto de vista da sociologia do corpo, Le Breton (2006) nos ajuda nesta reflexão

$4 \quad$ Os Karitiana constituem, como Povo Indígena do Estado de Rondônia, os únicos que falam a língua da família Arikém, uma das dez representantes do tronco linguístico Tupi Monde. Do ponto de vista histórico os Karitiana despontaram no século XX, sendo que a primeira referência a esse grupo na literatura data de 1909, pelo capitão Manoel Teophilo da Costa Pinheiro, um dos membros da Comissão Rondon. 
em busca de alguns pressupostos teóricos sobre as linguagens do corpo, afirmando que “antes de qualquer coisa, a existência é corporal”; com isso é possível reconhecermos que as relações com o corpo no contexto indígena vão além da dimensão biológica e estão presentes nos processos de ensino e aprendizagem. Assim como as percepções visuais, os gestos são idealizados e construídos nas estruturas sociais das diversidades culturais. Neste rumo, a linguagem do corpo das mulheres Karitiana pode revelar aspectos de comunicação e expressão que estão presentes nos processos de ensino e aprendizagem das práticas da educação indígena no contexto da comunidade.

Por meio de estudos identificamos que, no contexto comunitário, as mulheres indígenas desenvolvem práticas culturais em que os corpos falam comunicando a identidade cultural do Povo Karitiana e da língua Arikém. Nessa perspectiva, nos espaços cotidianos da aldeia, as mulheres desenvolvem atividades em que o corpo expressa movimentos que transmitem os processos de comunicação dos seus afazeres. Portanto, as representações e os movimentos do corpo perpassam necessariamente as relações construídas entre todas as ações vinculadas ao cotidiano da comunidade.

Para compreendermos melhor este olhar pesquisador, narraremos alguns afazeres femininos e a importância deles na aldeia, que revelam os processos próprios de ensino e aprendizagem com o uso da linguagem corporal. Uma pesca de pequeno rendimento, por exemplo, é realizada quase que cotidianamente por mulheres e crianças no igarapé da aldeia, mas seu produto - pequenos peixinhos, caranguejos e camarões de água doce conta mais como diversão, uma vez que os homens saem em datas específicas para a pesca mais distante; então o abastecimento diário é feito pelas mulheres.

Outra atividade que revela os processos próprios de ensino e aprendizagem com a linguagem do corpo está presente na confecção e comercialização dos artesanatos. A muIheres Karitiana produzem artesanatos, o que é uma das principais fontes de renda na aldeia. Esses artesanatos são vendidos diretamente na capital do Estado de Rondônia, Porto Velho, em feiras, festas populares, lojas ou nas ruas - ou por intermédio da loja da Associação Indígena Karitiana (Akot Pytim Adnipa, ou APK), entidade que repassa parte do dinheiro das vendas às artesãs. Para a produção desses artesanatos, as mulheres Karitiana usam 
o corpo na construção de formas geométricas, que são típicas de seu povo.

Em outro contexto observamos que é função exclusiva das mulheres Karitiana o cuidar, alimentar, acalentar, proteger e preocupar-se com os animais de estimação presentes na aldeia, já que são também elas que sentem e choram a morte deles.

[...] tais atitudes são salientes nos casos das mortes relativamente frequentes de cachorros: são as mulheres que ralham com seus maridos, entre sentidas e preocupadas, quando um cão é ferido ou morto durante expedições de caça, quando desaparece na floresta ou quando é agredido (às vezes fatalmente) por vizinhos e outros moradores da aldeia, mas o ônus emocional da perda recai majoritariamente sobre as mulheres (VANDER VELDEN, 2010, p. 164).

Nessa perspectiva, não podemos deixar de ressaltar que é função da mulher a maternidade, ao vermos a imagem da índia entrelaçada ao filho do seu corpo com a tipoia, uma das imagens mais simbólicas para descrever o significado da maternidade - "mãe e criança quase se fundem em um mesmo corpo", como nos descreve a antropóloga Lucia Helena Rangel. De acordo a pesquisadora, "a mãe cumpre um papel-chave na formação dos vínculos sociais e de pertencimento à família e a um povo" e esse é um dos motivos que garantem à maternidade um papel central. Essas práticas antropológicas ligadas aos valores maternos revelam práticas de ensino e aprendizagem que podem nos ajudar na compreensão dos fundamentos da educação Karitiana, e na compreensão dos processos próprios do ensino e aprendizagem.

Com este olhar pesquisador centrado nos estudos culturais pós-críticos, é possível afirmar que a mulher Karitiana possui uma identidade cultural de grande relevância para a compreensão da pedagogia do corpo na formação da infância indígena, considerando que toda a transmissão da cultura se faz pela mãe e ela tem plena consciência dessa relação cultural com os processos próprios do ensino e aprendizagem. Neste rumo, a mãe fala a língua do povo utilizando o corpo como prática de educar e cuidar da criança e é por isso que um menino ou menina indígena não fala português antes dos 4 anos de idade, ela cumpre um papel-chave na formação dos vínculos sociais e de pertencimento à família na construção da identidade cultural.

Dessa forma, identificamos que qualquer prática pertinente ao corpo é construída 
numa correlação dos processos próprios do ensino e aprendizagem da criança com o mundo, tornando-se um processo da identidade cultural Karitiana. São hábitos que são praticados visando sensibilizar a criança para os valores culturais do Povo Karitiana. Esses hábitos revelam formas de linguagem do corpo que demonstram outros meios de ensino e aprendizagem da cultura e identidade de um povo. Nesse caso, o corpo das mulheres Karitiana possui uma pedagogia que comunica os valores e as identidades culturais do seu povo.

Com base nesses pressupostos, podemos assegurar que o corpo é produtor social e cultural, considerando que cada povo cria o corpo de forma diferente, ainda que cada indivíduo estabeleça formas singulares de comunicação e expressão. Com isso, podemos afirmar que as mulheres Karitiana possuem uma pedagogia cultural com o corpo, que revela os processos próprios de ensino e aprendizagem. Neste rumo, afirma-se que a pedagogia do corpo das mulheres Karitiana demonstra que há um pertencimento desse corpo com as linguagens e códigos de sua cultura e identidade.

Dentro deste cenário epistemológico, reconhecemos que determinados grupos culturais possuem linguagens corporais que revelam processos próprios de ensino e aprendizagem. Com este olhar pesquisador, reconhecemos que é possível identificar linguagens corporais das mulheres Karitiana que são permeadas pela cultura e identidade indígena da comunidade. Com isso, o corpo como produtor cultural de identidades e das linguagens promove práticas culturais de ensino e aprendizagem que estão presentes no contexto da aldeia, vinculando essas práticas corporais aos fundamentos da educação indígena.

Esse território primordial onde a cultura vive em cada indivíduo. O lugar onde ela se manifesta e se revela sensível, viva. Dado que ela é aprendida desde o nascimento, admite-se que, até mesmo antes, é transmitida pelos mais velhos aos mais novos. Estes recebem-na sem contestação, inscrevem-na profundamente nas suas estruturas psicofisiológicas a partir de sua sensibilidade. Constituem as primeiras marcas, aquelas que vão ficar mais profundamente inscritas, integradas, no indivíduo. Impossível abandoná-las sem sofrimento (GRANDO; HASSE, 2002, p. 103).

Nesse contexto, podemos afirmar que o desempenho do corpo mostra a cultura adquirida no grupo e seu importante papel na construção dos processos de ensino e aprendizagem. Dessa forma, reconhecemos que o corpo é expressivamente marcado pela iden- 
tidade dos Karitiana, que transmite os processos próprios de ensino e aprendizagem na produção cultural. A mulher Karitiana possui uma função social importante em que o corpo revela valores importantes, demonstrando que ele está intencionalmente presente em todas as manifestações de linguagens dos processos próprios de ensino e aprendizagem.

\section{CONSIDERAÇÕES FINAIS}

As reflexões aqui apresentadas são apenas o começo da aventura científica de ir em busca das epistemologias dos olhares amazônicos para tornar a educação um ato de prazer e não de opressão. Introduzir conceitos das artes nas ciências talvez seja um grande desafio para um pesquisador das ciências sociais; assemelha-se à ruptura do sujeito com o objeto, da transnacionalização contra a regionalização e também do pensamento masculino contra o feminino. Mas o que se propõe, de fato, é um mergulho na condição complexa de uma visão global, arriscando a dizer que observamos mudanças gradativas nas artes, nas ciências, na educação ou em qualquer pensamento filosófico contemporâneo, relacionadas às epistemologias amazônicas (cf. GOMES; SATO, 2001).

Nessa perspectiva interpretativa dos estudos culturais pós-críticos, numa interface com os campos híbridos da educação ambiental, este estudo representa uma opção científica que visa contribuir com mais um pensamento pedagógico para tornar a educação um ato de libertação. Não resta dúvida que a determinação de um método pressuponha equilíbrio, estabilidade e funcionalidade na sensibilização das ações e reflexões do ser humano. Por isso, fizemos opção pelos estudos culturais pós-críticos.

Novos caminhos precisam ser criados paralelamente à revisitação de diversos outros estudos que necessitam buscar uma nova abertura para responder à complexidade ambiental no campo de uma possível pedagogia visual das epistemologias amazônicas. Reconhecendo que a educação não é o único caminho, mas aceitando que pode ser uma nova forma ética de metamorfose científica, este estudo ancora suas metas num projeto de EA que consiga compreender a força pedagógica como forma de libertação, para que novos postulados possam corroborar com a aliança entre cultura e natureza. 
Nesse contexto, acredita-se que o aporte da EA possibilita levar as pessoas a mudarem de atitude quanto aos graves problemas ambientais que afetam a humanidade. Sato (1999, p. 11) nos alerta que a "EA não é estudo do ser humano, nem isoladamente da sociedade e nem dos fragmentos da natureza. A EA deve se preocupar com a integração das três esferas, para conseguir alcançar um pensamento mais complexo, mais justo, que considere uma visão mais integradora da sociedade humana e de suas relações com a natureza".

Nessas trilhas da EA, este estudo pretende buscar construção do objeto desde a pesquisa por meio da análise de imagens fotográficas. Nesse sentido, algumas interrogações dentro do marco epistemológico da EA fazem-se imperativas. Na perspectiva fenomenológica, uma pesquisa não precisa indagar sobre uma situação-problema, mas pode ser desenvolvida por meio de interrogações, situações a serem analisadas ou percebidas.

Por fim, este estudo pretende contribuir para identificar a percepção do humano por meio de leitura imagética sobre a preservação e conservação dos recursos naturais de um bioma como o amazônico, visando construir estratégias de EA que possibilitem a elaboração de uma pedagogia visual para a sensibilização do ser humano com vistas à mudança de atitudes.

Para nós, inscrever-se na EA para proteção do bioma amazônico significa também reconhecer a estética visual que expressa os valores identitários dos seus habitantes. É, sobretudo, uma aprendizagem do saber histórico, etnográfico e ecológico de biorregiões que não possuem apenas suas belezas naturais, mas, sobremaneira, carregam marcas indeléveis da cultura e significados de esperanças.

Certamente teremos conflitos, em que as relações entre memória e identidade poderão ser problematizadas e para as quais muitas vezes não teremos respostas. Porém estamos cientes de que, mais do que naturalizar a sociedade, é preciso politizar o ambiente, circunscrevendo-nos aos recortes de vivências coletivas e individuais que promovam a metamorfose do mundo por meio das imagens.

O saber historiográfico a través das fotografias representa uma possibilidade pedagógica visual, inscrita na fenomenologia existencialista de jamais retirar o olhar de cada 
sujeito inserido nas suas relações de avizinhamento, de seus hábitos culturais, de seus saberes significativos e de sua maneira de ser no mundo. São identidades construídas num projeto político de vida, que devem ser ouvidas e registradas, incluindo-as nos processos decisórios e na formulação de políticas públicas. Uma proposição em EA, portanto, deve seguir um fio condutor do que a comunidade deseja, de quais são suas identidades e de como ela poderá participar, bem antes de propor projetos mirabolantes que podem satisfazer às políticas nacionais e internacionais do grande capital, mas que fracassam, pois se isolam das realidades vividas.

As fotografias são imagens que desfilam demonstrando que a beleza do meio ambiente não é mera iconografia natural, mas também possuem iconologia cultural de enorme grandeza. São como paisagens itinerantes, levadas e carregadas a vários mundos, para que a mediação pedagógica possa romper com limites espaciais ou territórios geográficos na inscrição de uma temporalidade em plena construção. São recortes de vidas transbordantes de sentidos, na mistura do exterior com o interior, que refletem as luzes de um pôr de sol amarelado com pinceladas purpúreas, ou, talvez com os olhares que jamais se cansam mesmo que as paisagens queiram cansá-los.

\section{REFERÊNCIAS}

BACHERLAD, Gaston. A poética do devaneio. São Paulo: Martins Fontes, 1988.

BARRETO, A.C.N.; BARRETO, J.M.M. A fotografia e o realismo - UFBA: Bahia, 2002. Disponível em: http://www.facom.ufba.br/labfoto.

DELGADO, S.M. O palco da imagem: o registro do teatro através da fotografia UFBA: Bahia. Disponível em: http://www.facom.ufba.br/labfoto. Acesso em: 04 out./ 2012.

DIEGUES, A.C. O mito da natureza intocada. $4^{\mathrm{a}}$ ed. Huicitec: Núcleo de Apoio à Pesquisa sobre as Populações Humanas em Áreas Úmidas. São Paulo: USP, 2002.

FREIRE, P. Educação como prática de liberdade. Rio de Janeiro: Paz e Terra, 1989, 150p.

FREIRE, P. Educação como prática da liberdade. $17^{\text {a }}$ ed. Rio de Janeiro: Paz e Terra, 1979. 
GADOTTI, M. Ecopedagogia, pedagogia da terra, pedagogia da sustentabilidade, educação ambiental e educação para a cidadania planetária. São Paulo, 2009.

Disponível em: http://www.paulofreire.org/Crpf/CrpfAcervoooo137.

GAUTHIER, J. Caminho pela desconstrução da hegemonia instituída na pesquisa. In:

GRANDO, B.S., FLEURI, R.M. Uma pesquisa sociopoética. Organizadores: GAUTHIER, J, GRANDO, B.S., FLEURI, R.M. Centro de Ciências da Educação - UFSC - Florianópolis: 2001.

GAUTHIER, J., GRANDO, B.S., FLEURI, R.M. Uma pesquisa sociopoética. Centro de Ciências da Educação - UFSC - Florianópolis: 2001.

GOMES, J.C.; SATO, M. Mulheres e homens: partes diversificadas da Terra. In VI Seminário Integrador: gênero, desenvolvimento e meio ambiente. Maceió, 2001.

GRANDO, B.; HASSE, M. Índio brasileiro, integração e preservação. In: Culturas no Plural: estudos emergentes. Reinaldo Fleuri (coord.) Grupo de Pesquisa Integrado/Educação Intercultural - UFSC/CED, Florianópolis, 2002 (p. 101-116).

IBAMA. Base, princípios e diretrizes: Diretoria de Unidade de Conservação e vida silvestre. [capturado] www.ibama.gov.br- em 06/11/02.

KOSSOY, B. Fotografia e história. São Paulo: Ática, 1989.

LAPA/UFSCAR. Unidades de conservação: análise de ecossistemas e monitoramento ambiental. [capturado] www.lapa.ufscar.br- em 06/11/02.

LE BRETON, D. Sociologia do corpo. Petrópolis-RJ: Vozes, 2006.

MAROTI, Paulo S. "Educação e Interpretação ambiental junto à comunidade do entorno de uma unidade de conservação”. São Carlos: 2002, 189f. Tese (Doutorado em Ciências) Programa de Pós-Graduação em Ecologia e Recursos Naturais, UFSCar.

. Conservação (Estação Ecológica de Jataí, Luis Antônio, SP). São Carlos-SP: PPG-ERN.UFSCAR, Dissertação de Mestrado, 1997, 115p. Artmed, 2005. Páginas 18 a 44.

MARQUES, J.G.W. Pescando pescadores: etnoecologia abrangente do baixo São Francisco. São Paulo: Huicitec, 1995.

MERLEAU-PONTY, M. Fenomenologia da percepção. Rio de Janeiro: Freitas Bastos, 1971. 
PARAÍSO, M.A. Metodologias de pesquisa pós-críticas em educação e currículo: trajetórias, pressupostos, procedimentos e estratégias analíticas. In: MEYER, Dagmar Estermann; PARAíSO, M.A. (org.). Metodologias de pesquisas pós-críticas em educação. Belo Horizonte: Mazza Edições, 2012.

PEDROSO JUNIOR, N.N. Etnoecologia e conservação em áreas naturais protegidas: incorporando o saber local na manutenção do Parque Nacional de Superagui. Dissertação de Mestrado. Programa de Pós-Graduação em Ecologia e Recursos Naturais. UFSCAR, São Paulo, 2002.

REZNIK, L.; GONÇALVES, M. História e fotografia: uma pedagogia do olhar. InFotografias contam a história de São Gonçalo [capturado] http://www2.uerj.br/ emdia/emdia215/ emdia.htm, em 22. Abril., 2005.

RUIZ, E.M. Como criar comunidade de aprendizagem. Revista de Educación, n 337 - Universidad de Granada - Colombia, 2005.

SANTOS, Boaventura. A crítica da razão indolente: contra o desperdício da experiência. São Paulo: Cortez, 2000.

SANTOS, J.E.; SATO, M. Universidade - Encontros e Despedidas. In: A contribuição da educação ambiental à Esperança de Pandora. São Carlos-SP: Rima, 2001.

SATO, M. \& SANTOS, J.E. Qual educação ambiental. In: Asociación de Docentes de Biologia de Argentina (ed.). Revista de Educación en Biología. V. 1, n² 2.5-21,1998.

SATO, M. Tele-educação ambiental: construindo utopias - Tópicos en educación ambiental - Guadalajara: SEMANARP, 1999.

SAUVÉ, Luci. “Uma cartografia das correntes em Educação Ambiental”. In: Educação Ambiental: Pesquisa e Desafios. Org. Michèle Sato e Isabel Carvalho. São Paulo:

Artmed, 2005.

VANDER VELDEN, F.F. De volta para o passado: territorialização e contraterritorialização na história Karitiana. Soc. e Cult. Goiânia: Soc. e Cult., v. 13, n 1, 2010. http://www.ihuonline.unisinos.br/index.php?option=com_content\&view=article\&id=3804\&secao=359. Acessado em 14/07/2016. 
Recebido em: 02/05/2019

Parecer em: 28/09/2019 Aprovado em: 01/11/2019 